\title{
MEMBANGUN EDUGAME "BONI KIDS - BORNEO ANIMAL KIDS” PERMAINAN MATCH-UP DENGAN TEKNIK PENGACAKAN SHUFFLE DAN PENGEMBANGAN AGEN CERDAS DENGAN MODEL FINITE STATE MACHINE (FSM)
}

\author{
Reza Andrea ${ }^{1)}$, Shinta Palupi ${ }^{2}$ \\ ${ }^{1}$ Teknik Informatika, STMIK Widya Cipta Dharma, Samarinda \\ ${ }^{2}$ Sistem Informasi, STMIK Widya Cipta Dharma, Samarinda \\ E-mail : reza@wicida.ac.id ${ }^{1)}$, shintapalupi@wicida.ac.id ${ }^{2)}$
}

\begin{abstract}
ABSTRAK
Penelitian membangun Edugame "Boni Kids - Borneo Animal Kids" merupakan penelitian pengembangan permainan berjenis Match-Up Game yang dirancang untuk mengasah daya ingat. Dalam permainan ini pemain harus mencocokkan 2 gambar hewan-hewan khas Kalimantan yang sama, pemain harus mengingat posisi gambar yang akan dicocokkan. Algoritma pengacakan shuffle diterapkan dalam penelitian ini, dengan tujuan membuat susunan posisi gambar selalu teracak dan permainan menjadi tidak monoton dan membosankan. Teknologi AI (kecerdasan buatan) juga diterapkan pada penelitian ini. Menggunakan metode model Finite State Machine (FSM), permainan yang dibangun akan memiliki karakter game agent yang akan mendampingi anak bermain layaknya guru.
\end{abstract}

Kata kunci: Boni Kids, match-up, edugame, shuffle random, FSM

\section{PENDAHULUAN}

Menerapkan game edukasi (edugame) sebagai media pembelajaran dapat melahirkan suasana baru yang menyenangkan dalam proses belajar. Gambar dan suara yang muncul membuat proses belajar tidak membosankan (Setiawati, 2008). Oleh sebab itu, dilakukan penelitian membangun Edugame "Boni Kids Borneo Animal Kids", sebuah permainan yang mengajarkan budaya Kalimantan dalam bentuk pengenalan hewan-hewan khas Kalimantan seperti burung enggang, babi rusa, payau, beruang madu, dan lainnya.

Dalam pembuatan permainan match-up yang mengasah daya ingat, objek puzzle pasangan-pasangan gambar tidak dapat di letakkan pada satu tempat posisi saja. Walaupun letak gambar tertutup, pemain pasti akan mengingat dimana letak pasangan gambar tersebut karena letaknya yang statis, hal ini akan membuat permainan tampak membosankan. Maka dilakukan teknik pengacakan shuffle random untuk mengacak posisi pasangan-pasangan gambar, dengan tujuan membuat permainan yang tidak statis dan membosankan. Sebuah teknik pengacakan yang diibaratkan pengocokan kartu.

Dikarenakan game yang dibangun adalah permainan edukasi. Maka dalam game yang akan dibangun ini, peran pendamping akan digantikan dengan hadrinya game agent. Agen permainan adalah karakter game yang dikontrol dengan cerdas memggunakan logika Finite State Machine (FSM). Logika FSM akan membuat karakter game yang mendampingi anak bermain dapat berfikir sendiri sesuai keadaan kondisi permainannya. Karakter dapat memberikan respon senang, marah, ataupun sedih sesuai gaya bermain anak.

\section{RUANG LINGKUP PENELITIAN}

Masalahan yang ada pada penelitian ini adalah:

1. Belum adanya penelitian mengenai membangun edugame berjenis match-up yang mengenalkan budaya Kalimantan dan hewan-hewas khas Kalimantan.

2. Banyaknya permainan yang tidak dimainkan lagi karena gameplaynya yang monoton dan membosankan.

3. Belum adanya edugame yang memiliki pendamping anak bermain dalam bentuk game agent dengan AI (kecerdasan buatan).

Tujuan dari penelitian ini adalah :

1. Membuat permainan mencocokan gambar (math-up game) yang mengangkat budaya Kalimantan.

2. Menerapkan shuffle random acak posisi dalam untuk mengacak posisi objek puzzle gambar.

3. Menginplementasikan logika Finite State Machine (FSM) dalam bentuk model kerangka berpikir yang akan diterapkan dalam agen karakter permainan.

\section{BAHAN DAN METODE}

Penelitian tentang game dengan teknik yang sama telah banyak dilakukan antara lain :

1. Teknik Pengacakan Posisi Objek Permainan "Find Me! - Bumi Etam" (Andrea, 2013) 
2. Teknik Pengacakan Arena Permainan "Find Me! Bumi Etam" dengan Teknik Shuffle Random (Andrea, 2015)

Dalam dua penelitian permainan Find Me!, player harus menemukan dimana objek karakter lucu "Nguknguk" bersembunyi. Arena tempat bersembunyi karakter lucu ini tidak dapat disusun dalam suatu urutan level biasa, karena hal ini pasti akan membuat permainan monoton dan membosankan. Menyusun urutan arena yang akan dihadapi oleh pemain dalam seiap level, harus dilakukan dengan teknik pengacakan shuffle. Sedangkan pada penelitian ini, teknik pengacakan shuffle akan diterapkan pada jenis permainan match-up. Penelitian ini juga menginplementasikan kecerdasan buatan dengan model FSM dalam bentuk game agent karakter hewan.

\subsection{Tahapan Penelitian}

Penelitian dilaksanakan melalui tahapan pengembangan multimedia sebagai berikut :

1. Mengkonsep gameplay dan cara penerapan algoritma yang digunakan, serta mengumpulkan materialmaterial pembuatan game.

2. Proses pengembangan edugame dengan metode pengembangan sistem multimedia, mulai dari desain sampai tahap assembly penerapan shuffle random dan FSM ke dalam sistem game.

3. Pemasangan aplikasi edugame ke dalam smartphone anak-anak dan guru PAUD.

4. Pendistribusian dan melakukan testing agar menghasilkan nilai persentasi yang memuaskan.

\subsection{Metode Pengacakkan Shuffle Posisi Objek}

Untuk menerapkan pengacakan posisi gambar dengan sistem shuffle random dilakukan dengan beberapa tahap berikut ini :

1. Menentukan jumlah pasangan gambar

Awal dari penerapan yaitu menentukan jumlah puzzle pasangan gambar dan menyusunnya layaknya sebuah matrik seperti pada gambar 1 .

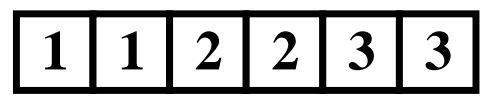

\section{Gambar 1. Matrik 6 × 1 Permainan Match-Up angka yang belum teracak}

Pada tahap ini dilakukan deklarasi nilai array seperti pada contoh script dibawah ini :

$$
A=\underline{\text { new } \operatorname{Array}}(1,1,2,2,3,3)
$$

Dimana nilai indek array yang pertama (indeks ke-0) adalah 0 , dan indeks terakhir adalah 5 .

2. Menyimpan setiap koordinat $x$ dan $y$ dari setiap puzzle gambar
Setiap objek gambar atau shape dalam project board permainan pasti memiliki koordinat $x$ dan $y$ seperti pada gambar 2 .

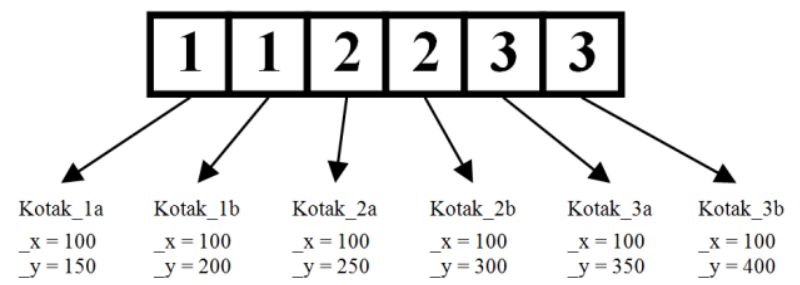

Gambar 2. Koordinat $x$ dan y dari 6 kotak gambar

Pada tahap ini keenam koordinat kotak gambar di catat dalam sebuah prosedur

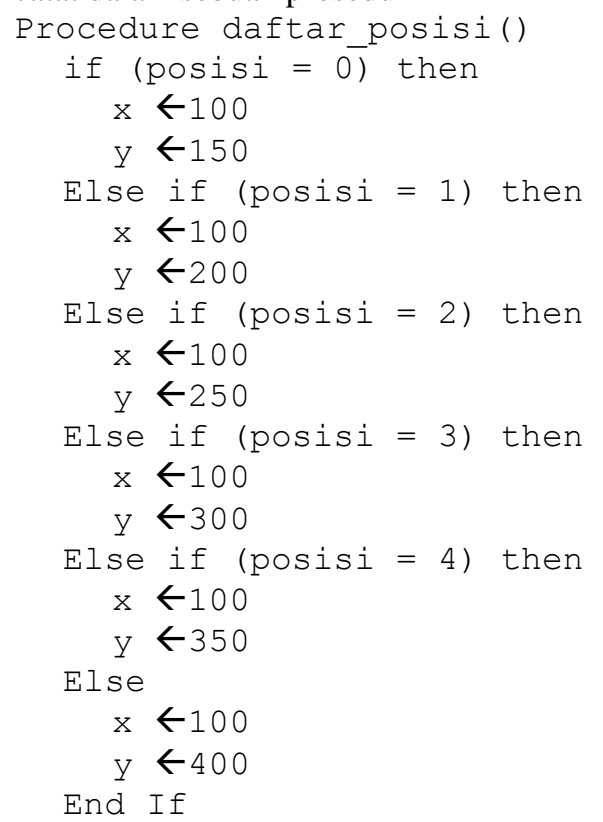

End Procedure

3. Pengkodean pengacakan posisi

Tahap terakhir adalah penggunaan fungsi shuffle random, serta pengacakan posisi koordinat dari setiap kotak puzzle gambar sesuai script pengacakan berikut ini :

$$
\text { posisi } \leftarrow \text { random.shuffle }(A)
$$

sehingga susunan matrik dapat teracak seperti gambar 3 di bawah ini :

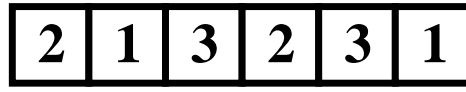

Gambar 3. Matrik 6 × 1 Permainan Match-Up angka yang telah teracak

\section{RANCANGAN SISTEM FSM}

Finite State Machine (FSM) atau juga disebut sebagai Finite State Automata, secara luas sebagai teknik untuk pemodelan fenomena atau kondisi berbasis event (Kyaw, Peters dan Swe, 2013). Perancangan FSM didasarkan pada event yang terjadi pada log aktifitas anak saat bermain. Waktu dan jumlah puzzle gambar tercocok menjadi prioritas kerangka pemikiran state 
FSM. Perilaku agen karakter hewan Kalimantan dirancangan dengan kerangka berbeda untuk setiap menu pembelajaran dan permainan, hal ini dilakukan untuk menciptakan agen dapat berperan sebagai pendamping sebaik mungkin. Berikut pada gambar 4 adalah statestate pada Finite State Machine yang diterapakan pada agen karakter hewan:

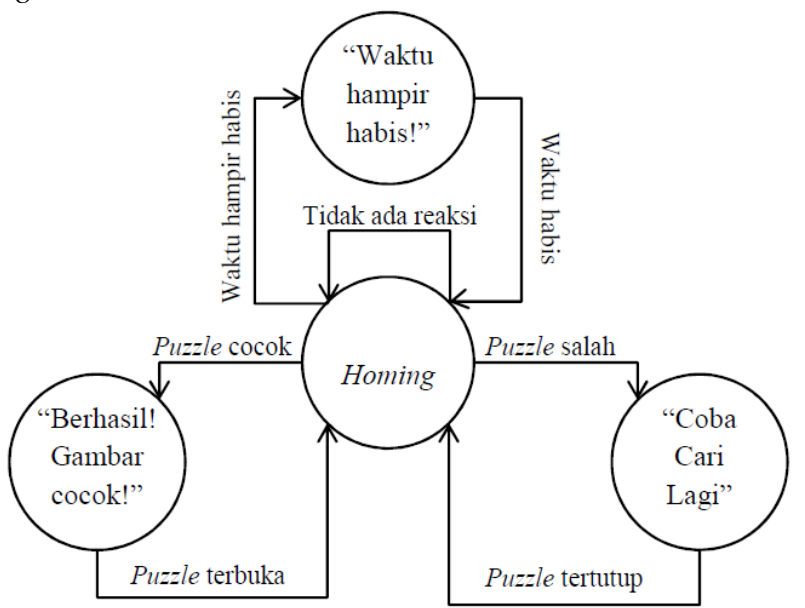

Gambar 4. Model logika FSM pada agen karakter hewan

Model di atas menjelaskan bahwa pada saat awal permainan, karakter hewan (agen) yang menjadi pendamping anak bermain dalam keadaan diam (homing). Karakter akan bergerak memberikan respon terhadap gaya bermain anak pada saat mencocokan gambar puzzle match-up. Pada saat 2 gambar puzzle yang terbuka cocok, maka karakter hewan akan memberikan respon senang, sebaliknya pada saat 2 gambar puzzle tidak cocok, maka karakter hewan akan memberikan respon sedih dan tetap memberikan semangat untuk menemukan gambar yang lain. Kondisi terakhir adalah pada saat waktu hampir habis, maka karakter hewan akan memberikan respon panik dan memberikan pengingat bahwa waktu hampir habis.

\section{IMPLEMENTAS}

"Boni kids - Borneo Animal Kids" adalah sebuah permainan edukasi Match-Up yang termasuk dalam kategori puzzle game yang dapat mengajak pemain bermain sambil belajar secara rileks, mudah dipelajari ataupun dimainkan oleh pemainnya. Konsep permainan ini memiliki aturan yang sederhana dan menampilkan konten yang dirancang untuk penggunanya untuk semua usia terutama anak-anak. Permainan ini memiliki empat menu pilihan pada scene opening yaitu belajar, bermain, about dan juga menu keluar,

Edugame ini memiliki aturan main yaitu pemain harus mencocokan gambar objek yang sama dari menu bermain, terdapat waktu di setiap level permainan yg dapat melatih kecepatan dalam mengingat objek yang sama yang akan di cocokkan dan juga terdapat score atau nilai di setiap level permainan yang telah dimainkan oleh pemain. konsep ini diassembly pada antarmuka gambar 5.

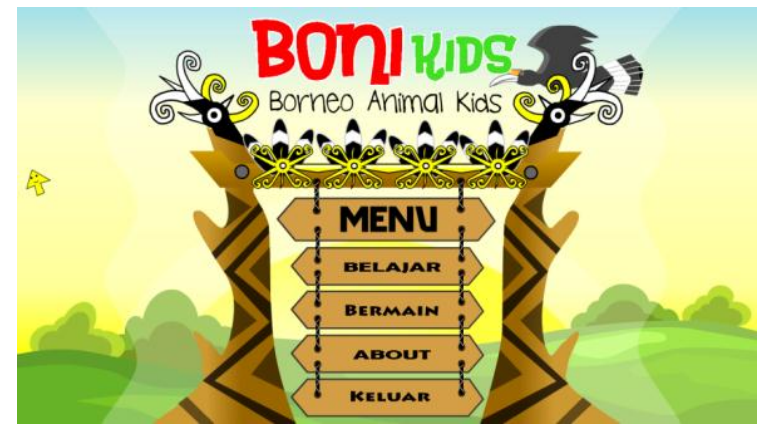

Gambar 5. Antarmuka scene opening "Boni Kids"

Pada menu belajar, pemain akan belajar cara memainkan game ini, dan dapat pula belajar mengenai informasi hewan-hewan khas Kalimantan dalam foto asli maupun dalam bentuk karakter lucu. (tampak pada gambar 6)

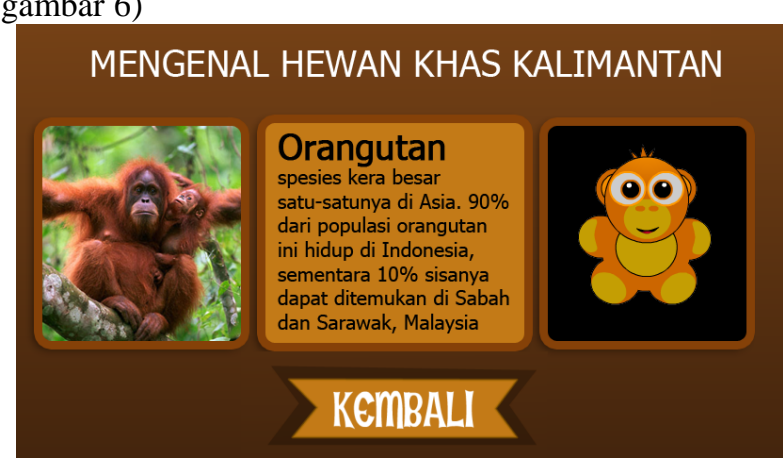

Gambar 6. Antarmuka scene belajar

Untuk memulai permainan, pemain harus menekan tombol bermain. setiap level permainan terdapat batasan waktu dan kesulitan yang berbeda : level 1 pemain diharuskan menyelesaikan waktu 45 detik mencocokkan objek gambar yg terdiri dari 12 kotak puzzle (lihat gambar 7); level 2 pemain diharuskan menyelesaikan waktu 55 detik mencocokkan objek gambar yg terdiri dari 16 kotak; level 3 pemain diharuskan menyelesaikan waktu 75 detik mencocokkan objek gambar yg terdiri dari 20 kotak puzzle.

Jika pemain kehabisan waktu sebelum dapat menyelesaikan permainan maka pemain dapat memilih mengulang atau kembali ke menu utama.

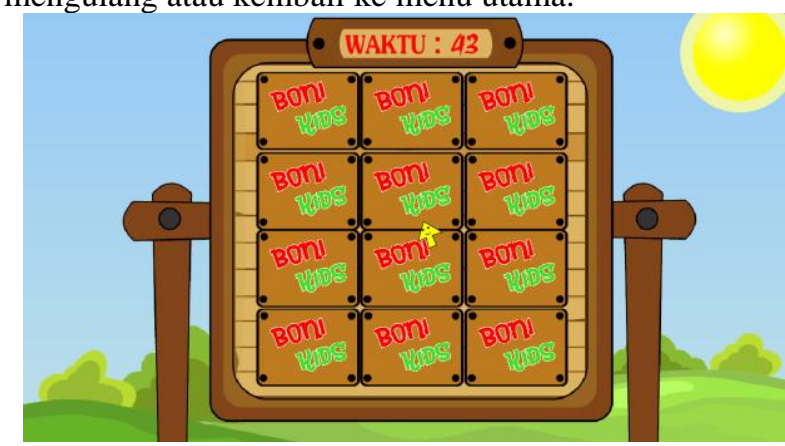

Gambar 7. Antarmuka scene bermain level 1 


\subsection{Assembly Pengacakkan Shuffle Posisi Objek}

Agar pemain tidak dapat menghafal posisi pasangan puzzle gambar yang tertutup di level match-up "Boni Kids", maka teknik pengacakan posisi kotak-kotak gambar harus dilakukan di setiap memulai level permainan. Artinya semua posisi gambar akan selalu berubah-ubah walaupun pemain memainkan permainan ini berulang-ulang.
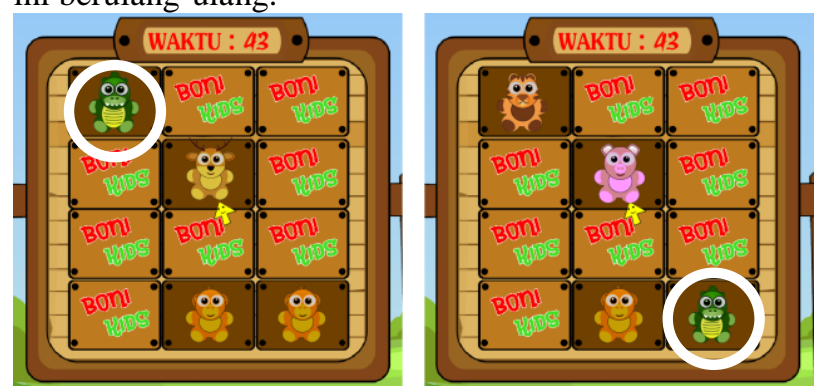

Gambar 8. Pengacakan posisi karakter buaya dalam puzzle Match-up

Seperti pada gambar 8, letak pasangan gambar buaya (tanda lingkaran) dapat berpindah-pindah secara acak di dalam matrik $3 \times 4$ tersebut. Dimana kemungkinan tertebaknya posisi 2 gambar yang sama di antara 12 kotak gambar tertutup adalah $2 \div 12 \times 100 \%=$ $16,7 \%$. Semakin banyak puzzle kotak gambar, maka semakin kecil peluang tertebaknya posisi pasangan gambar. Dengan adanya pengacakan posisi, pemain harus menebak dimana posisi pasangan gambar yang sama berada, dan pemain tidak dapat menghafal dimana posisi pasangan gambar disetiap memulai permainan, sehingga permainan tidak membosankan.

\subsection{Assembly Finite State Machine}

Model logika FSM (gambar 4) di terapkan sebagai pola ekspresi karakter lucu pada permainan, karakter lucu akan memberikan notifikasi apabila pemain salah atau benar mencocokan puzzle, dan memberikan notifikasi pada saat waktu hampir habis.

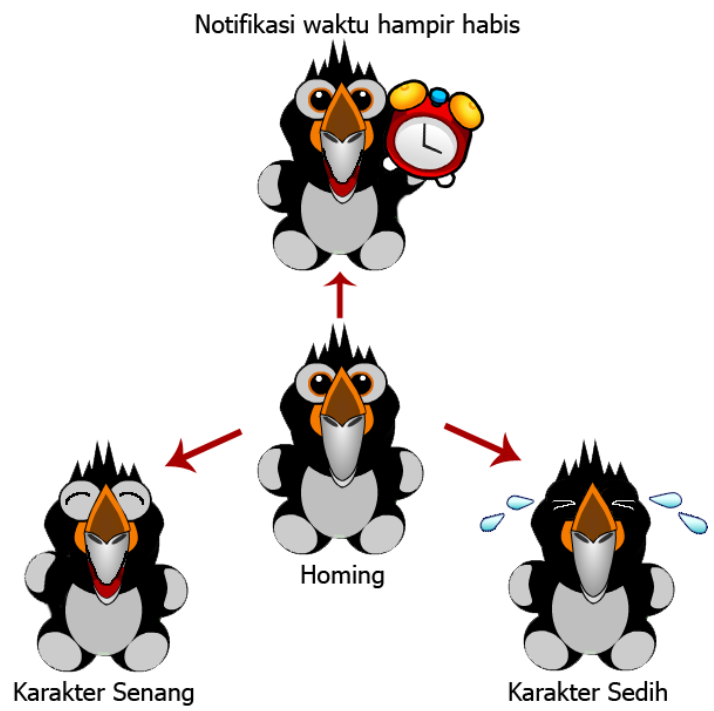

\section{Gambar 9. Notifikasi dalam bentuk ekspresi agen karakter hewan}

Dapat dilihat pada gambar 9 di atas, karakter hewan dapat memberikan ekspresi sedih, senang, ataupun panik pada saat waktu hampir habis. Logika FSM akan membuat notifikasi ini muncul sesuai dari aksi yang dilakukan pemain. Karakter hewan lucu juga dapat berbicara memberikan suara pemberitahuan layaknya guru pendamping bermain. Karakter juga dapat menangis apabila pemain kalah dalam permainan ini. (lihat gambar 10)

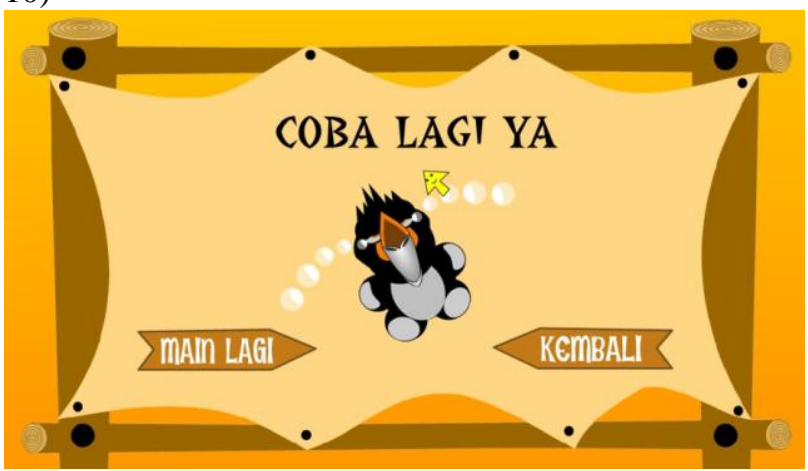

Gambar 10. Antarmuka scene kalah (game over)

Semua ekspresi ini dibuat dengan tujuan membuat antarmuka permainan menjadi lebih berinteraksi dengan pemain anak-anak. Sehingga anak-anak yang memainkan edugame ini merasa didampingi dengan hadirnya game agent.

\subsection{Pengujian Beta}

Pengujian beta merupakan uji coba sebuah aplikasi secara live didalam suatu lingkungan yang tidak dapat dikontrol oleh pengembang (Pressman ,2010). Uji coba dilakukan dalam bentuk quisioner sederhana yang diisi oleh guru dan siswa-siswi PAUD. Dalam penelitian ini uji coba dilakukan pada 2 orang guru dan 8 murid, dimana disajikan 2 pertanyaan yang mengacu pada gameplay dan peran game agent. Pertanyaan quisioner dibuat sesederhana mungkin agar anak-anak usia dini juga dapat mengisinya.

Tabel 1. Hasil pengujian beta

\begin{tabular}{|c|c|c|c|c|}
\hline \multirow{2}{*}{ Pertanyaan } & \multicolumn{3}{|c|}{ Jawaban Responden } & $\begin{array}{c}\text { Total } \\
\text { Respo } \\
\text { nden }\end{array}$ \\
\cline { 2 - 4 } & Bagus & Cukup & Kurang & 10 \\
\hline $\begin{array}{l}\text { Bagaimana } \\
\text { gameplay } \\
\text { edugame ini? }\end{array}$ & 7 & 2 & 1 & 10 \\
\hline $\begin{array}{l}\text { Bagaimana } \\
\text { peran karakter } \\
\text { hewan lucu } \\
\text { pada game? }\end{array}$ & 6 & 4 & 0 & $\mathbf{2 0}$ \\
\hline $\begin{array}{c}\text { Total } \\
\text { Jawaban }\end{array}$ & 13 & 6 & 1 & \\
\hline
\end{tabular}


Dari hasil pengujian beta pada tabel 1, dapat ditentukan bobot perhitungan untuk jawaban "kurang" memiliki bobot 1 , untuk jawaban "cukup" dengan bobot 2, dan jawaban "bagus" dengan bobot 3. Maka dapat diambil perhitungan rata-rata persentase nilai responden:

$$
\bar{X}=\frac{13 \times 3+6 \times 2+1 \times 1}{20 \times 3} \times 100=86.67 \%
$$

Berdasarkan perolehan persentase tersebut didapat persentase adalah $86.87 \%$, maka edugame "Boni Kids Borneo Animal Kids" ini dapat diterima karena presentasi nilai yang didapat, di atas nilai persentase minimum yaitu $50 \%$ (di atas cukup), dan mendekati angka $100 \%$ (sangat bagus).

\section{KESIMPULAN}

Dari hasil penelitian ini dapat diperoleh beberapa kesimpulan antara lain:

1. Telah dibangun edugame "Boni-Kids" permainan edukasi yang mengajarkan hewan-hewan khas kalimantan dalam bentuk permainan match-up. Pengembangan aplikasi dilakukan sesuai tahap pengembangan multimedia, mulai dari mengkonsep gameplay sampai pendistribusian aplikasi.

2. Teknik pengacakan posisi objek di dalam permainan match-up "Boni Kids" dilakukan dengan tujuan untuk mencegah pemain mengahafal posisi objek pasangan gambar tersebut dalam setiap level permainan, sehingga permainan menjadi tidak statis dan tidak membosankan.

3. Menghadirkan game agent sebagai karakter pendamping anak bermain. Finite State Machine yang diterapkan pada game agent, membuat karakter lucu pada permainan dapat berinteraksi sesuai logika aksi-reaksi dari gaya bermain pemain. Hal inilah yang membuat permainan edukasi lebih interaktif terhadap anak.

\section{SARAN}

Adapun saran dalam penelitian ini antara lain:

1. Teknik pengacakan bukan hanya diterapkan pada puzzle saja tetapi juga dapat diterapkan pada pengacakan arena stage permainan agar lebih menantang.

2. Pengembangan lebih lanjut pada logika FSM menggunakan moore machine agar karakter game agent lebih interaktif

\section{DAFTAR PUSTAKA}

Andrea, R. 2013. Teknik Pengacakan Posisi Objek "Find Me! - The Game. Prosiding Seminar Nasional Ilmu Komputer. 1 November 2013, Samarinda, Indonesia. Hal. 301-303.

Andrea, R. 2015. Teknik Pengacakan Arena Permainan "Find Me! - Bumi Etam" dengan Teknik Shuffle Random. Prosiding Seminar Nasional Teknologi Kompututer. 23 September 2015, Padang, Indonesia. Hal. 823-827.

Hurd, D dan Jenuings, E. (2009). Standardized Educational Games Ratings: Suggested Criteria. Longman. London.

Kyaw, A.S. Peters, C. and Swe, T.N. (2013). Unity 4.x Game AI Programming. Packt Publishing Ltd. Birmingham.

Poole, D.L. and Mackworth, A.K. (2010). Artificial Intelligence Foundations of Computational Agents. Cambridge University Press. New York.

Russell, S. J. and Norvig, P. (2011). Artificial Intelligence A Modern Approach Third Edition. Pearson Education, Inc. United States of America.

Pressman, Roger, S, (2010), Rekayasa Perangkat Lunak: Pendekatan Praktisi. Andi

Setiawati. (2008). Education Games. Proumedia. Jakarta.

\section{Publikasi ini dibiayai oleh:}

Direktorat Riset dan Pengabdian Masyarakat

Direktorat Jenderal Penguatan Riset dan Pengembangan Kementerian Riset, Teknologi, dan Pendidikan Tinggi sesuai dengan Kontrak Penelitian Tahun Anggaran 2017 